\title{
Problems of Practice As Stance
}

\author{
Edmund 'Ted' Hamann, PhD \\ University of Nebraska-Lincoln \\ ehamann2@unl.edu \\ Guy Trainin, PhD \\ University of Nebraska-Lincoln \\ gtrainin2@unl.edu
}

\begin{abstract}
This piece describes a steadily changing, teacher leadership-oriented, CPED-affiliated, education doctorate $(E d D)$ program that is housed in a department of curriculum and instruction. It situates the program design in relation to four key concepts-epistemology, praxis, efficacy, and iterative processes-while highlighting CPED's core stance that the voice of the professional practitioner needs to be inserted into discussion of educational change, not as the target of policy, nor the object of research, but rather as a coequal partner in a research/policy/ practice triad in which practitioner insights related to context are key for the viability of educational efforts.
\end{abstract}

KEYWORDS: epistemology, praxis, efficacy, iterative

\section{INTRODUCTION}

Shortly after the creation of the Carnegie Project for the Education Doctorate (CPED), which sought (and seeks) to distinguish the Education Doctorate, or EdD, from the Doctorate of Philosophy in Education, or PhD, CPED articulated six Principles of Program Design. The sixth principle is "Emphasizes the generation, transformation, and use of professional knowledge and practice" (CPED, n.d., Guiding Principles for Program Design section, para. 6). This is a different and more applied role than the traditional emphasis of university research to generate new knowledge. This different emphasis comes with its own inevitable paradox-we are telling practitioners (who are also our EdD students) that they offer a unique and crucial perspective that should inform educational praxis-i.e., that they already bring crucial expertise-but also that they must honor the traditional orientations of the university to acquire credentials establishing their expertise. In the words of Cochran-Smith and Lytle (2009):

The knowledge needed for teachers to teach well and to enhance students' learning opportunities and life chances [can]not be generated solely by researchers who were centrally positioned outside of schools and classrooms and imported for implementation and use inside the schools. (p. vii)

Yet we are also telling our practitioner inquirers that, for policymakers and researchers to heed their voices, they should acquire advanced credentials taught not as embedded professional development, but rather as advanced university coursework (i.e., by us). They should be heeded, but only with our support and attending to at least some of our institutions' academic trappings.
Our goal here is to describe how our cohort-based CPED program, now in its fifth iteration, illuminates how the generation, transformation, and use of professional knowledge can be embedded in design and intentionally pursued, but we start with the caveat above because we have found that an absence of understanding of principle six by various stakeholders has been one of the most significant challenges to our program. Although we gain nothing by "naming names" (and thus will not), we have faculty colleagues both within our department and elsewhere in the university who we have found resist the idea of practitioner inquiry.

Early on with our first cohort, for example, we had an external doctoral committee member who was adamant that our student could not study her own professional environment to take on a "problem of practice" because clearly she was an interested party in relation to that environment. Instead, that committee member required her to find another similar site to her own workplace and to conduct her dissertation research there.

This committee member's insistence did not derail the completion of a viable dissertation, but it did distort the program design. It meant our student needed to convey lessons from a nearby site (with which she had less stake) to bring them back to her own. We use the term "less stake" advisedly in the last sentence, because it is not the same as "no stake". For verisimilitude purposes, our student went to a neighboring district to the one where she worked. While she did not have direct professional responsibilities in that setting, the reason she was able to arrange a study there is because she knew colleagues there, had attended professional development activities with them, and shared paperwork if/when students had moved from her jurisdiction to theirs. So she did have a stake in remaining in their good graces. None of her accommodations were "bad", nor "indefensible", but they are a
New articles in this journal are licensed under a Creative Commons Attribution 4.0 United States License.

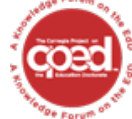

This journal is supported by the Carnegie Project on the Education Doctorate: A Knowledge Forum on the EdD (CPED) cpedinitiative.org 
reminder that a committee member's expectation of disinterested research conditions was unachieved (and likely unachievable).

Wolcott (1992) reminds us that the very act of deciding to study one thing versus another inserts interest. He notes this is not a fatal flaw, just a factor that needs to be made explicit to readers so that those readers can account for it. To make a further point, we want educators to be interested, to care about the well-being of their students and colleagues. It follows that from at least the first half of the term "practitioner-researcher" we are expecting CPEDers to be interested rather than disinterested parties.

\section{CPED Doctoral Students Are Interested Parties}

CPED students are interested parties in relation to various problems of practice and usually that interest ties to their professional responsibilities as practitioners. That interest is both inevitable and a virtue as, going back to Cochran-Smith and Lytle (2009), it creates a perspective too readily overlooked in traditional education research. We expect practitioners to be advocates-to worry about the students in their charge, or the parents with whom they collaborate on the creation of Individualized Education Plans, or the teachers for whom they are curriculum coordinator, etc.-but in our experience it is not inevitable that our fellow university faculty colleagues who could contribute to CPED will concur with this stance.

Our CPED program starts with recruitment, proceeds with early induction (including orientation into a cohort), and continues with each participant crafting a "Roadmap to Candidacy" that asks them to articulate: (a) biographically how they came to a particular problem of practice, (b) how they tie that problem to educational theory (i.e., a "stance" [Cochran-Smith \& Lytle, 2009] or "posture" [Wolcott, 1992]), (c) how methodologically they might proceed to gain insight into that problem of practice to inform new or transformed practice, and (d) how they tie their inquiry into a larger area of emphasis (e.g., language, literacy, and culture; STEM [science, technology, engineering, and math] education; or social analysis, educational policy, and reform). With the Roadmap to Candidacy doubling as the written comprehensive exam, our CPED students then start to work on a dissertation of practice.

During recruitment and then during early course activities that, among other tasks, try to build a sense of belonging to a cohort, we constantly highlight to the CPED students that it is because they are practitioners that they are good candidates for an EdD. Furthermore, we emphasize (and they quickly see) how their classmates share the challenges of juggling family and full-time job responsibilities with the ambition of wanting to attain advanced degrees.

\section{Four Words}

Course syllabi connect our program's operation to the more abstract language of the sixth principle. For example, the "Challenges and Opportunities" introductory course (which spans CPEDers first two semesters) starts by identifying four words that define the program: "Epistemology, Praxis, Efficacy, and Iterative" ("iterative" replaced the word "reflection" used with our first cohort). We clarify that "epistemology" describes the study of what constitutes knowing and that professional knowledge is obviously a centrally relevant kind of knowing. The term "praxis", in turn, is intentionally a little different than just practice; the word highlights practice that is informed by theory. Thus it ties in purpose and intentionality. It invokes practice that is not just action, not just doing it because "you're supposed to do it", but rather professionally informed action in which the practitioner (i.e., the CPED doctoral student) can articulate why they are doing what they are doing. "Efficacy" is a reminder that educational practice is supposed to create/produce something. Phrased as a question, how do CPED practitioners know that what they are doing is accomplishing what they are setting out to do? This raises the specter of things like external assessments, observation protocols, and the like (and these fit), but, like praxis, it also presumes the practitioner's capability at articulating what counts, what success looks like. Finally, the term "iterative", which references going back to do things again and again, echoes the rhythms of school-teaching third grade last year, this year, and next year-but also introduces the idea of design research, that in each iteration things are modestly adapted and retooled based on how prior renderings were and were not efficacious.

\section{Other Principles}

We also propose that the "generation, transformation, and use of professional knowledge" (i.e., the sixth principle) partially encompasses the third and fifth CPED principles, with the use of professional knowledge overlapping with "demonstrate collaboration and communication skills" (from the third principle) and the generation and transformation of professional knowledge emerging from the task of developing "a professional knowledge base that integrates both practical and research knowledge, that links theory with systemic inquiry" (from the fifth principle; CPED, n.d., Guiding Principles for Program Design section, para. 5). So our CPED program intentionally illuminates how our programmatic practice is grounded in collaboration and communication and how it continuously connects theory and practice.

Following McDermott (1977) and others (e.g., Hamann \& Reeves, 2012), our CPED design notes that both universal and contextual dynamics affect what students do and how they fare at school. It follows that what expert practitioners should do-in Hamann and Reeves' words, the "necessarily in situ decision making that is characteristic of teaching" (p. 97) -is not only "what always works." Appropriate instruction is the combination of what works and what works here, with the latter crucial and particularly visible to practitioners, but harder for external researchers to access.

Experiment-control logics (what the founding director of the federal Institute for Educational Sciences called "the gold standard" of education research [Hamann, 2003, p. 442]) can yield interesting insights that can inform educational practice, but they can never provide all of the needed insight as to what should happen. We would not need teachers if what should happen in a classroom could be fully defined by universalism-oriented research, but good teachers know that effective instruction is transactional, that it includes knowledge not just of students (generically) but of these students (particularly). Good teachers translate, and adapt and supplement what is generally effective to what is effective here and for now. If CPED's raison d'etre is to help advanced practitioners take on problems of practice, then it follows that we need to promote and honor an epistemology that accounts for the in situ knowledge that is part of good practice. While our program focuses on teacher leadership, it is not hard to imagine modest substitutions for a few words above and making similar claims about education administrators negotiating a similar conjunction of broadly true knowledge and wisdom that applies "this time" to "this situation." 
Turning to the next word-praxis-then is not much of a shift. If praxis references theory-informed practice, or purposeful practice, it follows that praxis emerges from the epistemologically inclusive frame that accounts for both the universal and the particular. One of the key advocates of relating the idea of praxis to pedagogy was Paulo Freire (1970), the Brazilian educator and theorist, whose core premise for adult literacy instruction (his early career task) was that learners needed to "know the word to know the world" (p. 87), with the working premise that the words learners needed to know varied according to their particular circumstances. Each learner needed words to describe their own necessarily autobiographic circumstances and the words necessary to advocate for changing those circumstances in an emancipatory fashion. Thus praxis also embeds the particular, or contextual, but beyond that, as Freire's term emancipatory foreshadows, it connects to CPED's first principle which promises that program design "is framed around questions of equity, ethics, and social justice to bring about solutions to complex problems of practice" (CPED, n.d., Guiding Principles for Program Design section, para. 1).

Both praxis and epistemology put CPED at odds (at least partially) with dominant educational policy currents. While the rigor and ambition of the Standards Movement has much to recommend it, that movement is intrinsically generic-here is what everyone needs-and thus incomplete. As a book that we have all of our CPED enrollees read attests (see Proefriedt's High Expectations [2008]), the Standards Movement does not attend to what a specific learner wants to learn (which may vary from another learner with different interests), nor, in Freirian (1970) sense, what a particular learner needs to learn (per the premise that because circumstances vary, what will be emancipatory also varies).

We know that our program exists at a historical moment in which our effort to help practitioners assert and hone their expertise coexists with an opposite impulse to 'teacher proof' curricula and pedagogy. Our program design rejects the drive to "teacher proof" curricula because such efforts reject the logic of praxis-that practitioners should be able to adapt practice for theoretically defensible purposes that respond to the immediate circumstances of an educational environment. This leads to consideration of the third word, efficacy-what "counts" as an effective practice environmentand perhaps the most important premise of CPED, i.e., what constitutes the "the generation, transformation, and use of professional knowledge and practice" or principle six.

\section{Practitioners as Experts}

Counting the perspectives of practitioners as "expert", as worth attending to, which we think CPED does, then has key and disruptive implications for a more traditional imagining of the roles of education research and the university in relation to educational policy and practice. The university is not supposed to tell skilled practitioners what they should do. However, that does not mean there is no role for the university (why would CPED exist if there was no role?). CPED offers a place for practitioners to learn the languages of research and policy, in a sense to remain practitioners but concurrently become more than practitioners. Through a cohort approach it allows practitioners to network with other practitioners who also are identifying and taking on problems of practice, with the premise that "even as others' problems are different from mine I can learn from their strategizing and enacting."
Ultimately we find ourselves using the language of "design research" (Bannan-Ritland, 2003; Design-Based Research Collective, 2003). This describes how our program has iteratively transformed over its five (and counting) renderings and how we want CPED participants to pursue their own problems of practice. Applying a design research lens to our program design has included logistic as well as theoretical dimensions. As an example of the former, we have come to realize that while state department of education (SDE) personnel would be an attractive population for our program, our dependence on the seasonality of schooling (and the availability of summer for intensive coursework) runs counter to SDE employees' need to concentrate their work activities in the summer. So summer is a poor time to enroll SDE employees. As a more theoretical example, we have come to learn which of our faculty colleagues in our department and across the university are willing to embrace CPED's emphasis on transformation (i.e., application of inquiry to one's site of practice) and which others cannot get past the idea that research should be positivistic and disinterested (both stances that conflict with practitioner's practitioner responsibilities). Honoring the principles of CPED means challenging and changing how at least one corner of the university operates.

\section{REFERENCES}

Bannan-Ritland, B., (2003). The role of design in research: The integrative learning design framework. Educational Researcher, 32(1), 21-24.

Carnegie Program on the Education Doctorate (n.d.). About us. Retrieved from: http://www.cpedinitiative.org/page/AboutUs

Cochran-Smith, M. \& Lytle, S. L., (2009). Inquiry as stance: Practitioner research for the next generation. New York, NY: Teachers College Press

Design-Based Research Collective, (2003). Design-based research: An emerging paradigm for educational inquiry. Educational Researcher, 32(1), 5-8.

Freire, P. (1970). Pedagogy of the oppressed. New York, NY: Continuum

Hamann, E. T., (2003). Reflections on the field: Imagining the future of the anthropology of education if we take Laura Nader seriously. Anthropology and Education Quarterly, 34(4), 438-449. Retrieved from http://digitalcommons.unl.edu/teachlearnfacpub/43/

Hamann, E. T., \& Reeves, J. (2012). Accessing high-quality instructional strategies. In T. Timar \& J. Maxwell-Jolly (Eds.), Narrowing the achievement gap: Perspectives and strategies for challenging times (pp. 95-110). Cambridge, MA: Harvard Education Press. Retrieved from http://digitalcommons.unl.edu/teachlearnfacpub/134

McDermott, R. (1977). Social relations as contexts for learning in school. Harvard Educational Review 47(2), 198-213.

Proefriedt, W. (2008). High expectations: The cultural roots of standards reform in American education. New York, NY: Teachers College Press.

Wolcott, H. (1992). Posturing in qualitative inquiry. In M. LeCompte, W. Millroy, \& J. Preissle (Eds.), The handbook of qualitative research in education (pp. 3-52). San Diego, CA: Academic Press. 